\title{
Recursos naturales y delimitación de fronteras en América Latina en la primera globalización: una aproximación desde la Guerra del Acre
}

\section{Natural resources and borders delimitation in Latin America in the first globalization: an approach from the Acre War}

\begin{abstract}
Melisa Janet Luc
Lic. en Economía (Universidad Nacional de Córdoba, Argentina). Magister en Historia Económica (Universitat de Barcelona, Universitat Autònoma de Barcelona y Universidad de Zaragoza). Doctoranda en Historia de la Facultad de Filosofía y Humanidades de la

Universidad Nacional de Córdoba, Argentina.

http://orcid.org/0000-0002-0960-9686

memeluc@gmail.com

Fecha de recepción: 3 de febrero de 2014

Fecha de aprobación: 15 de julio de 2014
\end{abstract}

Sugerencia de citación: Luc, M. (2015). Recursos naturales y delimitación de fronteras en América Latina en la primera globalización: una aproximación desde la Guerra del Acre.

tiempo\&economía, 2(1), 69-88, 


\section{Resumen}

En este trabajo se busca integrar más variables al análisis histórico económico de América Latina, vinculando los procesos de independencia, la formación de los Estados y la determinación de sus fronteras con las posibilidades de desarrollo a finales de la primera globalización. Estos argumentos se han concretado en el estudio de un caso particular: la Guerra del Acre. En el mismo se pone de manifiesto que la disponibilidad de recursos naturales no fue exógena a las economías de los países participantes sino que respondieron a decisiones políticas e intereses económicos internos. Además, se ponen de manifiesto algunas de las diferencias políticas y económicas de Brasil y Bolivia en el siglo XIX y se vinculan con las diferentes posibilidades de desarrollo que tuvieron estos países.

Palabras clave: América Latina, fuerza de los Estados, guerras fronterizas, delimitación de fronteras y posibilidades de desarrollo.

Codigos JEL: N46, N56.

\section{Abstract}

The objective of this work is to integrate more variables to the economic historical analysis of Latin America, linking the processes of independence, the formation of states and borders delimitation with the possibilities of development by the end of the first globalization. These arguments were concentrated in the study of one particular case: the Acre War. In these cases, it evidenced that the availability of natural resources was not exogenous to the economies of the participating countries, but responded to political decisions and domestic economic interests. In addition we highlight the political and economic differences of Brazil and Bolivia in the nineteenth century, and link this with the different development possibilities of these countries.

Keywords: Latin America, States strength, frontier wars, borders delimitation and development possibilities.

JEL Codes: N46 , N56. 


\section{Introducción}

Existe una extensa literatura sobre la evolución económica de América Latina para el siglo XIX. El desempeño económico de estos países ha intrigado a muchos intelectuales que han intentado explicar por qué tuvieron (y tienen) patrones de crecimiento y desarrollo económico tan dispares a lo largo del tiempo, en especial, a finales de la primera globalización.

Bulmer-Thomas (2000) se centra en la idea de la teoría de la lotería de bienes ${ }^{1}$ para explicar las diferencias regionales de desarrollo a principios del siglo XX. Así, aquellos países que dentro de sus fronteras se encontraron con recursos que generaban una demanda internacional importante o creciente implementaron un modelo de crecimiento guiado por las exportaciones que les permitió crecer, en mayor o menor medida, dependiendo de los eslabonamientos hacia atrás y hacia adelante y de los efectos de arrastre que generaba el bien que se exportaba.

Esta teoría no ha sido la única hipótesis relacionada con los recursos naturales que se ha utilizado para explicar los patrones de crecimientos dispares de los países de América Latina en el siglo XIX. Entre algunas de las teorías que existen se puede mencionar la hipótesis de la geografía, de la cual hay muchas versiones diferentes. Quizás la más común es aquella que relaciona el clima con los ingresos a través del efecto sobre el trabajo. Por otro lado, están las hipótesis de la geografía sofisticada, que presentan algunas variables interesantes; entre ellas está la "temperate drift hypothesis", la cual establece que la geografía se vuelve importante frente a ciertas tecnologías (Acemoglu et al., 2002, pp. 1233-1234).

Otras teorías relacionadas con factores geográficos establecen que hay zonas que, dada su geografía, son más propicias para que se den los procesos de industrialización con mayor facilidad, como tener salida al mar, contar con ciertos recursos naturales como el carbón o el petróleo, entre otros (Acemoglu et al., 2002, p. 1234).

Existen también teorías que analizan el desarrollo de las instituciones desde las colonias, teorías institucionalistas, centrándose en la idea de que fueron las instituciones coloniales las que condicionaron o favorecieron las posibilidades de desarrollo de los distintos países, Douglas North es el mayor referente de esta teoría. Su propuesta es que las diferentes condiciones iniciales - principalmente, las diferencias existentes en la política y la religión de las colonias inglesas y las españolas - son responsables de las diferencias en el rendimiento de estas sociedades a través del tiempo (Prados de la Escosura, 2006, p. 468).

Acemoglu, Johnson y Robinson (2002), en esta línea, desarrollan la hipótesis de las instituciones. Los autores relacionan la organización de las sociedades y la creación de las instituciones desde la época colonial, entendiendo que las condiciones en ciertas sociedades hacían más propicia la generación de instituciones que aseguraban derechos de propiedad efectivos a un amplio sector de la sociedad. Se refieren a este grupo como instituciones de propiedad privada y las comparan con las instituciones que ellos denominan extractivas. ${ }^{2}$

1 Término acuñado por primera vez por Días Alejandro (en 1970) pero desarrollado por Bulmer-Thomas, debido a que, como destaca el autor en el prefacio de su libro La historia económica de América Latina desde la Independencia, Díaz Alejandro murió joven. Bulmer-Thomas (2000, p. 9).

2 Las instituciones extractivas se dan a través de la concentración del poder económico y político en un peque- 
Los autores argumentan que el colonialismo europeo condujo a una reversión institucional, ya que aquellas zonas que eran relativamente más prósperas ${ }^{3}$ antes de la colonización europea terminaron siendo las menos prósperas con el paso del tiempo. Así, la hipótesis de las instituciones, junto con la reversión institucional, pronostica un retroceso en los ingresos relativos de las zonas de América Latina más ricas para el siglo XV. En su análisis, los autores destacan el rol esencial del cambio tecnológico que se dio en el último cuarto del siglo XIX, ya que no es hasta este momento que comienza a observarse un retroceso en los ingresos de estas sociedades (Acemoglu et al., 2002).

Como se puede observar, no sólo ha sido cuestión de debate lo referente a la evolución económica de América Latina y el porqué de su atraso económico, sino que también se ha discutido cuándo se dio este atraso. Bulmer-Thomas, Coatsworth y Haber se adhieren a la tesis de que este atraso comenzó a darse en el siglo XIX (Prados de la Escosura, 2006, p. 463, y Arroyo Abad, 2013). Estas teorías entienden que la integración de estos países a la economía mundial fue la fuerza dinámica que generó las desigualdades entre los países de América Latina.

Acemoglou et al. (2002) se adhieren a lo que suele denominarse "teoría de las dotaciones" (Arroyo Abad, 2013). Estas teorías establecen que la dotación inicial de las colonias determinó las formas que tomaron las instituciones, y que estas persistieron en el tiempo, por lo que son estas instituciones las que explican gran parte de los resultados económicos actuales de estos países.

Por otro lado, mucho se ha discutido sobre las causas y consecuencias económicas de las independencias de los países de América Latina. Si bien es cierto que no hay consenso en cuanto a las causas de la independencia, parece haber un relativo acuerdo en cuanto a algunas de las consecuencias que estos procesos tuvieron sobre estas regiones. En términos económicos, el consenso se encuentra en los siguientes puntos: en cuanto a los efectos positivos, se mencionan el fin del monopolio con la península Ibérica y el acceso a los mercados internacionales de factores y de créditos; en cuanto a los efectos negativos, se destacan el fin de la unión aduanera, la fuga de capitales y el colapso del sistema económico colonial (Prados de la Escosura, 2006, p. 466).

La diversidad de explicaciones acerca de los orígenes del atraso económico y la disparidad de trayectorias regionales en América Latina contrasta con la escasez de evidencias empíricas para el período de la postindependencia. Lo interesante por destacar es que las teorías anteriormente mencionadas no centran su estudio en el período de formación de los Estados, ni en el período de creación y de asentamiento de una soberanía nacional sobre un territorio. El hecho de centrar el presente estudio en ese período y relacionar estas variables con las posibilidades de desarrollo para el siglo XIX constituye la principal contribución de este trabajo.

Es por ello que se plantea la siguiente pregunta: ¿Qué impacto tuvieron los procesos de independencia, la formación de los Estados y la delimitación de fronteras en las posibilidades de desarrollo de estos países en el siglo XIX? Hasta 1850 no se acaban de consolidar los Estados nacionales, ni están definidos los límites fronterizos, ni son reconocidos los gobiernos

ño grupo poderoso, generando un ambiente poco propicio para las inversiones.

3 Los indicadores que utilizan los autores para determinar la prosperidad de las sociedades antes del siglo XV son los niveles de urbanización y la densidad poblacional de estas sociedades precoloniales. 
latinoamericanos por todos los actores sociales. Por ser un momento conflictivo y confuso, su estudio carece de la profusión de trabajos que tienen en la literatura sobre historia económica de América Latina tanto los períodos precedentes de la Colonia como los posteriores de la primera globalización.

Sin embargo, es un período clave. Si bien la demanda internacional de bienes fue la fuerza dinámica que movilizó los recursos de los nuevos países para especializarse y desarrollarse económicamente a fines del siglo XIX, también es cierto que las disputas territoriales, que se llevaron a cabo durante todo el siglo XIX y continuaron durante el siglo XX, fueron motivadas por intereses económicos (García Pérez, 2005).

Este trabajo se centra en analizar, por tanto, las posibilidades de exploración, expropiación y adquisición de recursos naturales por parte de los países de América Latina y la construcción de un Estado con la posibilidad real de hacer valer su soberanía sobre su territorio, intentando aproximarse a una visión más particular e individual de cada país, entendiendo y justificando las decisiones políticas y económicas tomadas por estos nuevos países frente a posibilidades económicas internacionales e intereses económicos que aprovechar. Se buscará demostrar que este análisis no puede desvincularse de los resultados económicos que estos países tuvieron a principios del siglo $X X$.

La hipótesis, por tanto, se centra en la siguiente idea: los países que tuvieron la fuerza y los recursos políticos, militares y económicos necesarios para poder hacerse valer como un Estado nacional soberano en su territorio, y que fueron reconocidos por todos sus ciudadanos y por los demás países que los rodeaban, además de poder ampliar sus fronteras, fueron quienes pudieron desarrollarse más.

Aunque el presente trabajo tiene la ambición de relacionar la formación de los Estados, la delimitación de fronteras y las posibilidades de desarrollo para los países de América Latina en el siglo XIX, esta primera aproximación se realiza a través de un estudio de caso concreto: la Guerra del Acre. El conflicto ha sido escogido por ser un buen ejemplo de cómo los intereses políticos y económicos precedieron a la delimitación de fronteras y, a la vez, a la disponibilidad de los recursos naturales que iban a ser cruciales en el desarrollo económico de los países implicados. En futuros desarrollos de esta investigación se prevé incorporar otros casos que, al igual que el aquí considerado, reflejan la hipótesis teórica que se mantiene.

El primer capítulo contiene una justificación teórica de estas ideas y unas líneas teóricas propuestas para trabajar más a fondo la hipótesis que se plantea. Luego se indaga más sobre las cuestiones referentes a las disputas entre estos países, buscando en la historia de la creación de los Estados de Brasil y Bolivia pruebas de la hipótesis que se sostiene. Allí se expone un breve resumen de los procesos políticos, las condiciones económicas y la determinación de fronteras entre estos dos países.

\section{Algunas líneas teóricas propuestas}

La investigación presente se adhiere a la idea de que los factores políticos y militares internos de los países de América Latina son claves para entender el desarrollo económico de los mismos en el período analizado. Cabe destacar que no se dejan de lado factores como la 
lotería de bienes, la dotación inicial de recursos y las instituciones que se formaron desde las colonias. Pero sí se insiste en estudiar el período de formación de los Estados y la delimitación de fronteras, ya que estos factores están vinculados al éxito (o al fracaso) económico de estos países.

Para empezar, deben considerarse los procesos de independencia como claves para el análisis. Los Estados latinoamericanos nacieron en un período de luchas, y, por lo tanto, las consecuencias económicas, políticas y sociales de estos procesos son claves para el análisis por realizar. Entre algunos de los autores que han escrito sobre este período se encuentra Prados de la Escosura (2006), el cual determina que las consecuencias de las mismas fueron la fragmentación del poder político, la militarización de la sociedad y la movilización de recursos y hombres para la guerra. El autor establece que, una vez culminado el proceso de independencia, la agitación política en el continente continuó, en parte, porque comenzaron las disputas sobre las fronteras nacionales, y en parte, porque las guerras civiles continuaron afectando los procesos políticos de estos países jóvenes y nuevos (Prados de la Escosura, 2006, p. 466).

En segundo lugar, es necesario entender la relación existente entre las variables determinación de fronteras y obtención de recursos, ya que esto permitirá entender las posibilidades de desarrollo de estos países en el período de la postindependencia. Para ello, se hace referencia al artículo de Caselli et al. (2013), titulado "The geography of inter-state resource wars". La hipótesis de este trabajo es que las probabilidades de conflicto entre países son elevadas cuando al menos un país tiene recursos naturales para explotar, y esta probabilidad será aún mayor si estos recursos se encuentran cerca de las fronteras comunes. Los autores logran relacionar los factores delimitación de fronteras y obtención de recursos naturales, entendiendo que aquellos que ganan las guerras fronterizas se apropian de estos recursos y los explotan, proporcionando mayores recursos a la economía nacional y ampliando las posibilidades de desarrollo. Este tipo de trabajos supone la consideración de la delimitación de la frontera como un factor endógeno al modelo económico, una consideración que suscribe la presente investigación al considerar que la disponibilidad de recursos estuvo fuertemente vinculada al poder político, militar y económico de los Estados en formación.

En tercer lugar, Jean-Paul Deler (2008) es quien resalta el papel fundamental del Estado en los procesos de consolidación del territorio nacional, estableciendo que, en el caso de los países de América Latina, "se afirmó el control territorial de los Estados más poderosos sobre espacios que eran objeto de litigios de soberanía" (Deler, 2008, p. 37). Deler entiende que la fuerza de los Estados latinoamericanos fue clave en la definición de fronteras en el período analizado, y esto fue así, debido a la existencia de recursos valiosos en fronteras no del todo definidas o poco claras. Entonces, cabría preguntar: ¿Fueron más fuertes aquellos Estados que ganaron las guerras fronterizas? Según la tesis de Deller, sí, pero en todo caso ¿qué determinó que ganaran la guerra? O dicho de otra forma, ¿qué factores determinaron la posibilidad real de un Estado de apropiarse de un territorio? ¿Tener poder económico? ¿Tener poder político dentro y/o fuera del país? ¿Poder movilizar a su población para ocupar estos territorios? ¿Contar con el apoyo de alguna potencia mundial que respaldara económicamente las guerras y financiara los procesos de desarrollo económico?

Por último, es importante destacar que los estudios de historia económica suelen subestimar la fuerza de los Estados latinoamericanos en el siglo XIX; la tesis de Carmagnani (1984) es 
un claro esfuerzo por superar esta dificultad. El autor establece que las estructuras productivas en el último cuarto del siglo XIX sufrieron una serie de transformaciones que, en muchos casos, no requirieron grandes cambios estructurales (ya que donde se criaba ganado vacuno se podía criar ganado lanar, que Bulmer-Thomas denominó modelo aditivo ${ }^{4}$ ). Pero en otros casos, los obstáculos que sí se presentaron fueron superados por una oligarquía claramente dinámica y con cierto poder: "La clase dominante, por sí misma o en estrecha relación con el capital inglés, fue capaz de superar los obstáculos. Ello significaba que las oligarquías poseían el dinamismo necesario para no dejarse doblegar fácilmente" (Carmagnani, 1984, p. 33).

Caramagnani (1984) contradice la idea de Bulmer-Thomas de que sólo las estructuras productivas pueden explicar el desarrollo económico de los países de América Latina. Aquellos países que cambiaron sus estructuras productivas porque el sector exportador se los demandó pudieron hacerlo porque la clase dominante tuvo la fuerza para superar los obstáculos necesarios para ello. No introducir esta variable en el análisis lleva a simplificar demasiado las fuerzas que operaron en este período y, por lo tanto, las razones de las diferencias económicas para principios del siglo XX.

En lo que sigue del trabajo, se buscará indagar más sobre las cuestiones referentes a las disputas entre países limítrofes, intentando introducir al análisis histórico-económico factores políticos y militares para poder relacionar las tres variables consideradas relevantes: la fuerza de los Estados, la ampliación de fronteras y las posibilidades de desarrollo, a partir de un estudio de caso particular. Así, se intentará introducir las decisiones de política interior y la variable frontera como factores endógenos a las posibilidades de desarrollo económico, entendiendo que las señales de los mercados internacionales fueron una gran motivación económica para estos países jóvenes y recientemente independizados.

\section{El caucho: ¿suerte o disputa?}

De La Condamine, a mediados del siglo XVIII, vislumbró al mundo occidental con las propiedades del caucho, sustancia obtenida del látex de ciertos árboles que se encontraban en la cuenca del Amazonas (ver el mapa 1). Las notables características del caucho, su elasticidad e impermeabilidad, fueron ampliando las posibilidades de aplicación de la sustancia, y se fueron abriendo, muy lentamente, nuevos mercados en Occidente. Ya para fines de 1780, el caucho estaba presente en varios mercados: se hacían botas, morrales, tubos, catéteres, gomas de borrar, globos, etcétera. A principios del siglo XIX, la ciudad de Belém do Pará (colonia portuguesa) exportaba zapatos de caucho a Nueva Inglaterra, y en 1813 se abrió en Francia una fábrica de ligas de caucho. Aunque el mercado comenzó a ampliarse y las exportaciones ya eran considerables, su explotación a escala industrial estaba limitada por su gran sensibilidad a los cambios de temperatura, que alteraban notablemente la calidad del producto (Ullán de la Rosa, 2004, p. 184).

4 Bulmer-Thomas (2000, p. 105). 
Mapa 1. Mapa de la cuenca hidrográfica del Amazonas

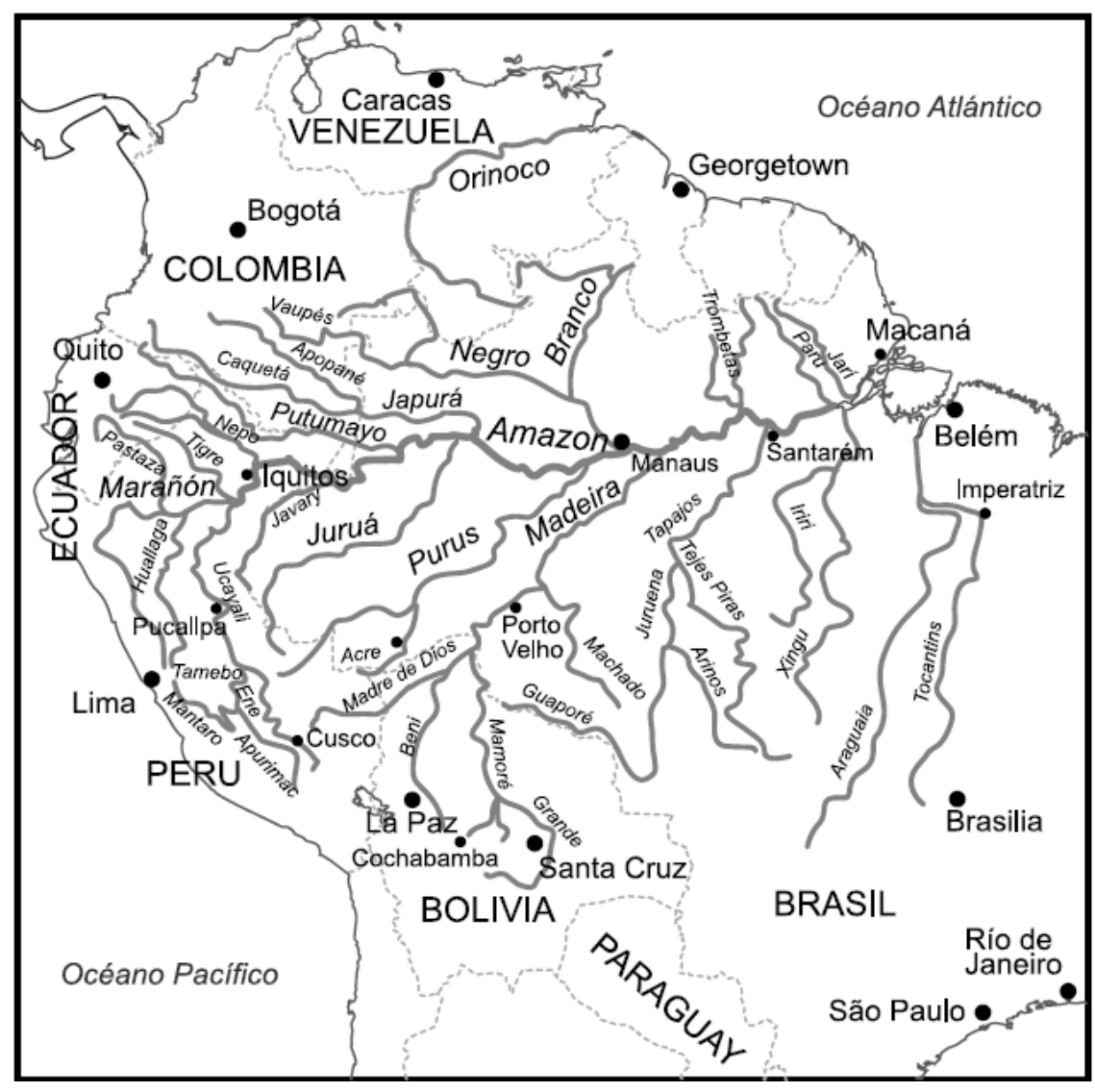

Se llama cuenca hidrográfica del Amazonas a la masa de agua que fluye por la Amazonia. Cubre una superficie de 6,2 millones de $\mathrm{km}^{2}$ y forma parte de varios países de América del Sur: Perú, Colombia, Bolivia, Ecuador, Venezuela, Guayana y Brasil. Este último tiene dentro de sus fronteras la mayor extensión de la cuenca.

Fuente: elaboración propia con base en el mapa http://commons.wikimedia.org/wiki/File:Amazonriverbasin_basemap.png.

Como explica Ullán de la Rosa (2004), la explotación del caucho se expandió cuando se generaron los procesos necesarios para la fijación de sus propiedades, proceso denominado vulcanización, que permitió una expansión de su demanda, además de nuevas posibilidades de usos.

La vulcanización puso las bases para la definitiva explotación industrial del caucho, cuyo impulso definitivo vendría de la mano de la invención de la rueda neumática en 1888 por Dunlop [...]. El neumático convirtió al caucho en una materia prima de importancia estratégica mundial y en un motor económico de primera magnitud para los países de la Cuenca Amazónica. (Ullán de la Rosa, 2004, pp. 184-185)

España y Portugal, a lo largo de los siglos XVII, XVIII y XIX, firmaron varios tratados, con el fin de delimitar los territorios pertenecientes a cada país. Entre los acuerdos firmados se encuentran el Tratado de Tordesillas (1494), el Tratado de Madrid (1750), el Tratado de San Ilde- 
fonso (1777) y el de Badajoz (1801) (Zambrana Lara, 2011, p. 6). En todos estos tratados, que fueron ampliando el territorio de dominio portugués, la región del Acre, que abarcaba unos $355.242 \mathrm{~km}^{2}$ aproximadamente, figuraba como de dominio español (ver el mapa 2).

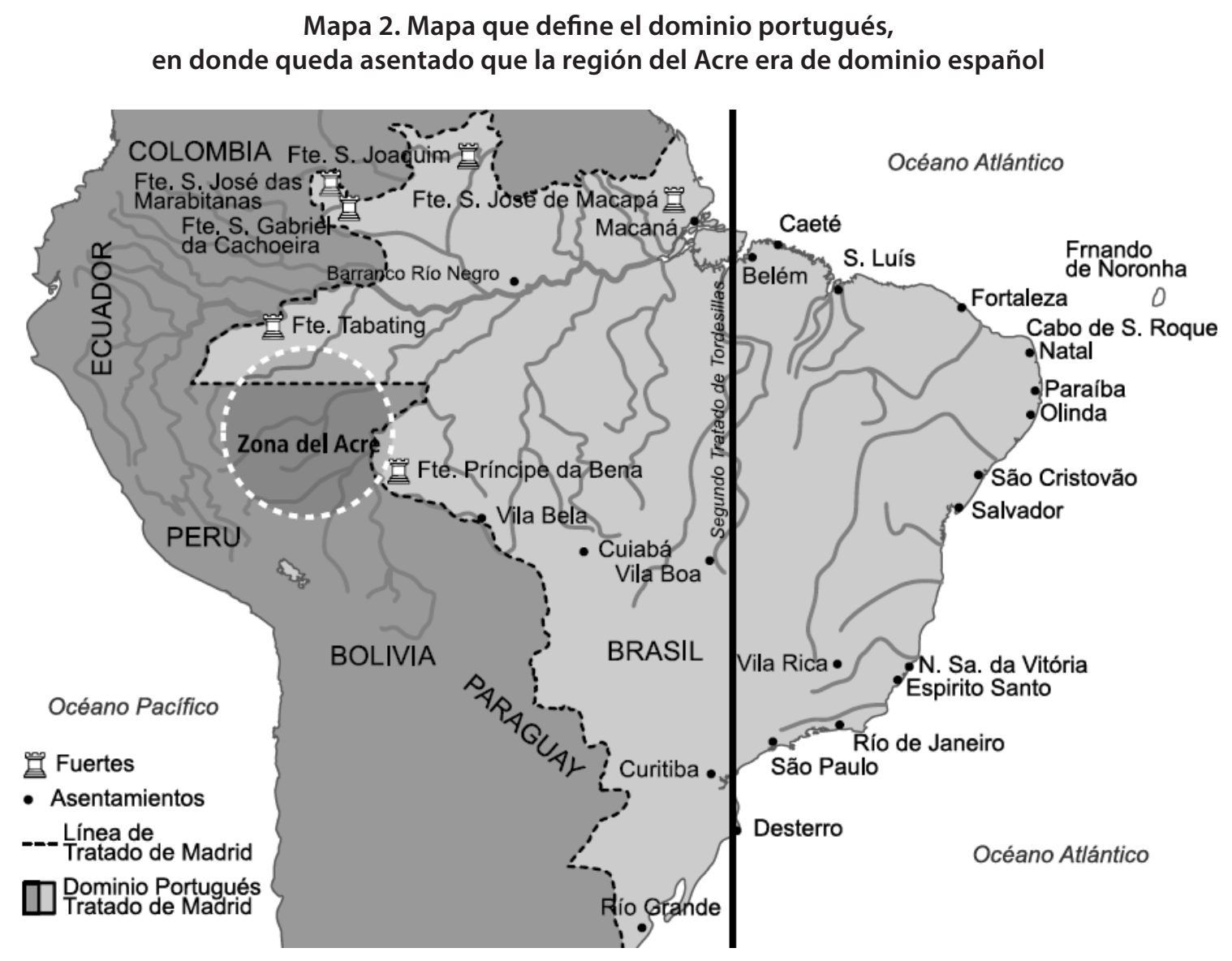

Fuente: elaboración propia con base en el mapa: http://noss2geografia.blogspot.com.es/2012/02/o--territorio-legalizado--os--tratados.html.

Los procesos de independencia de Brasil y de Bolivia, así como sus primeros años como economías autónomas e independientes, trajeron aparejados distintas problemáticas ; una de ellas fue la delimitación de las fronteras entre estos dos países. Para poder entender las relaciones entre las variables establecidas y las posibilidades de desarrollo, a continuación se lleva a cabo un breve resumen de las características de las economías bolivianas y brasileras en el siglo XIX, así como también se analizan los procesos políticos y la dinámica de sus economías internas.

Bolivia se independizó en 1825 sobre el territorio de la colonia Audiencia de Charcas. La vinculación de Bolivia con el mundo exterior se daba a través de tres nexos: con la ruta que iba al Atlántico por Buenos Aires (el que perdió importancia cuando se independizaron las 
repúblicas del Río de la Plata y el coste del transporte aumentó); con su puerto en Cobija, el único puerto boliviano y su única salida al mar, y con el puerto de Arica, puerto peruano por donde se exportaban también algunos productos bolivianos (Bonilla, 1991, p. 223).

La historia política de Bolivia está segmentada entre períodos de golpes y contragolpes por parte de los caudillos militares para hacerse del poder y saquear los pocos recursos del Estado. "En este contexto de inestabilidad política, incluso de anarquía, el gobierno de Andrés Santa Cruz (1829-1839) constituyó una notable excepción" (Bonilla, 1991, p. 226). El gobierno de Santa Cruz fue el primer intento de ordenar la economía y la política del país, además de que se buscaron nuevas salidas al mar para romper con el aislamiento del exterior; pero por lo que más se lo recuerda es por el intento frustrado de lograr la unidad andina entre Bolivia y Perú (Bonilla, 1991, p. 226). A partir de 1840 y hasta 1849 se contabilizaron 65 golpes de Estado; claramente, este entorno no era el propicio para crear un proyecto nacional compatible con un proceso de crecimiento y desarrollo económico (Bonilla, 1991, p. 230).

Autores como Prados de la Escosura (2006 y 2009) y Peres Cajías (2011) destacan el shock institucional que generan los procesos de independencia, debido a la expulsión de una burocracia imperial y a la generación de un nuevo Estado. Esta transición puede generar costos económicos que perduren en el largo plazo, afectando las posibilidades de desarrollo (Peres Cajías, 2011, p. 2). La inestabilidad política que tuvo Bolivia en este período, ineludiblemente afectó a su economía y condicionó su inserción en el mercado internacional a fines del siglo XIX.

Al observar distintos indicadores económicos de Bolivia para el siglo XIX, se puede ver que, si bien no hubo necesariamente un estancamiento económico en el período de la post-independencia, es uno de los países con menos dinamismo económico de América Latina (Peres Cajías, 2011, pp. 3-4). Aun así, a partir de 1850 la economía boliviana se reactivó, debido al renacimiento de la actividad minera (plata), dando lugar a la exportación de plata y a la entrada de capitales extranjeros al país (Bonilla, 1991, p. 233).

Así, para finales de 1870, Bolivia se convirtió en uno de los mayores exportadores de plata del mundo pero, lamentablemente, esto no se vio reflejado en una mejora en la posición económica boliviana respecto de sí mismo o de sus países vecinos. Bonilla (1991) argumenta que la escasa mano de obra y el trazado de las líneas de ferrocarriles no favorecieron la vinculación entre los distintos sectores y regiones, por lo que tampoco favorecieron el crecimiento de este sector (Bonilla, 1991, p. 233). Esta visión ha sido discutida por varios autores, ${ }^{5}$ quienes se han preguntado por qué la minería boliviana no tuvo el impacto que otros sectores exportadores tuvieron sobre los países latinoamericanos después de la independencia (Peres Cajías, 2011, p. 8). Más allá de las razones de estas limitaciones, el sector exportador boliviano tuvo límites claros para afectar al resto de la economía.

En cuanto al sector agrícola boliviano - que tenía como estructuras básicas las haciendas y las comunidades de indios-este era pequeño y producía quina, coca, maíz, trigo y papa. Las dos primeras eran las más comercializables en los mercados internacionales, aunque su presencia era muy precaria (Bonilla, 1991, p. 224, y Peres Cajías, 2011, p. 4).

Otro sector económico importante para Bolivia era su litoral, parte del desierto de Atacama, en donde se encontraban asentadas empresas chilenas, inglesas y francesas desde 1840,

5 Peres Cejías (2011) entre otros. 
las cuales explotaban cobre y guano. Entre 1857 y 1866, en la región de Mejillones, se descubrieron yacimientos salitreros que fueron explotados principalmente por capital chileno e inglés y fueron colocados en el mercado internacional. Esto hizo del puerto de Antofagasta el puerto más importante de Bolivia; así lo describe Bonilla (1991): “Desde 1868, el puerto de Antofagasta, cuya población, como la de Cobija, era en más del $90 \%$ chilena, se convirtió en el puerto principal del litoral boliviano" (Bonilla, 1991, p. 235). Es interesante destacar que estas exportaciones eran libres de impuestos (Sicotte et al., 2008), por lo que el Estado no percibía beneficios directos por la explotación de estos territorios.

La decisión del Gobierno boliviano de cobrar impuestos a las exportaciones de esta región desató la Guerra del Pacífico, en 1878, la cual tuvo como protagonistas a Chile, Bolivia y Perú (los últimos dos, aliados) (Palma, 2003). Respecto de esta guerra sólo se destacará que para principios de la década de 1880, Bolivia había perdido una guerra, recursos naturales y el territorio que le correspondía desde la Colonia del desierto de Atacama. La Guerra del Pacífico fue devastadora, $y$, frente a la búsqueda de un nuevo sector exportador que permitiera a Bolivia salir de la situación complicada en la que se encontraba, el caucho llamó la atención no sólo de los empresarios bolivianos sino también de su Gobierno (López Beltrán, 2001, p. 576).

La magnitud del fenómeno del caucho y el histórico abandono de esas alejadas tierras preocuparon al Gobierno, que consideró de inminente necesidad la incorporación de esos territorios al control estatal. Aun así, este no era el único objetivo del Gobierno; debido a la pérdida de la salida al mar en la Guerra del Pacífico, el Estado boliviano buscaba una salida al mar por el Atlántico (López Beltrán, 2001, p. 579, y Zambrana Lara, 2011, p. 7).

El caso de Brasil, a diferencia del caso boliviano, es bastante excepcional, ya que en términos políticos se mantuvo unido, centralizado y, además, experimentó una transición relativamente pacífica hacia la independencia, ya que se dio una aparente continuidad institucional.

La transición hacia la independencia se caracterizó por la presencia de la Corte portuguesa a principios del siglo XIX en territorio colonial, debido a la presencia de Napoleón en Portugal. Esto cambió la dinámica de la colonia porque las decisiones de política económica dejaron de tomarse en el exterior, aunque el papel central del sector exportador permaneció casi intacto (Bethel y Carvalho, 1991, pp. 323-324; Dean, 1992, p. 335). Los conflictos económicos entre los terratenientes y los comerciantes portugueses llevaron a que el 7 de septiembre de 1822, Pedro I, el príncipe regente de la colonia portuguesa, declarara la independencia de Brasil y se autoproclamara emperador. Estructuralmente, no hubo un cambio significativo en el paso de uno a otro (Prados de la Escosura, 2009, p. 285); de hecho, muchos cargos políticos que estaban ocupados por portugueses siguieron en las mismas manos (Dean, 1992, p. 335). El proceso de creación de un nuevo Estado se compaginó, por tanto, con la convivencia de portugueses y brasileros, dentro y fuera del mismo, lo que generó un tire y afloje que no culminó hasta el fin del Imperio (Dean, 1992, p. 335).

Más allá de esto, Brasil es considerado un caso particular, en comparación con el resto de las colonias de América Latina, ya que el país no sólo logró reducir el shock institucional del proceso de independencia sino que además logró instituciones que protegieron a los grupos económicos de la agresión y la expropiación de sus recursos (Prados de la Escosura, 2009, p. 285). 
El Imperio, que comenzó en 1822 y duró hasta 1889, no siguió ningún objetivo económico de forma enérgica, y si bien se propusieron algunos proyectos nacionales, se llevaron a cabo sólo unos pocos. Se caracterizó por una dinámica clientelista hacia las clases altas y desanimó a aquellos empresarios capitalistas con ideas innovadoras. El comienzo de la República, a partir de 1889, cambió la política económica, se buscó promocionar la dinámica de crecimiento guiado por las exportaciones, y se liberó el "espíritu de asociación". Aun así, se debe destacar que los gobiernos civiles que continuaron también seguían intereses propios (Dean, 1992, p. 337).

La economía brasilera fue próspera y diversa desde la Colonia, además de haber estado siempre orientada al sector exportador. Desde 1500 hasta 1822, los colonizadores impulsaron la producción de muchas materias primas diferentes, gracias a las características climáticas y geográficas de la región. La diversificación de productos impulsada consistió en la producción de algodón, índigo, arroz, cacao, tabaco, café y azúcar. En el siglo XVIII la explotación extractiva del Amazonas consistía en la comercialización de oro, ${ }^{6}$ madera de tinte, cacao, pieles, plumas, loros, esencias, ipecacuana, zarzaparrilla, entre otros (Dean, 1992, p. 334).

La independencia de Brasil tampoco modificó estructuralmente la economía extractiva que venía desde la Colonia (Bevilaqua y Pavia Abreu, 2003, p. 61; Prados de la Escosura, 2009, p. 292, y Haber y Klein, 1993, p. 154). Haber y Klein (1993) sostienen que"la independencia de Brasil no supuso un inmediato cambio importante en la dirección del comercio", ya que hasta 1830 no tuvieron que buscar nuevos compradores para sus exportaciones tradicionales ni tuvieron que generar nuevas exportaciones para nuevos mercados; además, resaltan el hecho de que el volumen del comercio exterior no varió considerablemente en el corto plazo (Haber y Klein, 1993, p. 154).

Así, el cultivo del café siguió concentrado en el sureste de Brasil, trasladándose a mediados del siglo XIX a las zonas cercanas a Río de Janeiro. La producción de caña de azúcar se concentró en el noreste, al igual que el algodón. En el sur se exportaban cueros, pieles, tasajo, madera y mate, y en la zona amazónica se exportaba el caucho, entre muchos otros productos (Bevilaqua y Pavia Abreu, 2003, p. 61). Para finales del siglo XIX, el caucho representaba un elevado porcentaje de las exportaciones totales de Brasil; entre 1890 y 1899 el 14,2\% del total de las exportaciones era de caucho, y entre 1900 y 1909 este porcentaje había ascendido a 25,6\%7 (Bevilaqua y Pavia Abreu, 2003, p. 57).

Dean destaca cómo los brasileros se interesaron en la región del Acre, ya que allí se encontraba la seringa Hevea brasiliensis, el árbol de caucho más buscado por los productores, debido a sus características particulares y, sobre todo, por su alta productividad, en comparación con los otros árboles caucheros (Dean, 1992, p. 343). “En Belém, cerca de la desembocadura del Amazonas, otro tipo de caucho llamó la atención de las autoridades coloniales portuguesas. Este tipo se llamaba seringa o sirynge, caucho de su aplicación más antigua" (Dean, 1987, p. 9; traducción de la autora).

Las exploraciones en el Acre se hicieron tanto por el lado de Brasil como por el lado de Bolivia. Brasil alcanzó la región a través de los ríos Purus y Madeira, además de que se llevaron a cabo expediciones para reconocer tanto la zona como sus características climáticas, poblacionales y de producción (López Beltrán, 2001, pp. 579-583, y Zambrana Lara, 2011, p. 8).

6 La fiebre del oro duró un siglo en las zonas de Minas Gerais, Goiás y Mato Grosso. Dean (1992, p. 334).

7 Es en esta última década que Brasil amplía su frontera obteniendo la región del Acre. 
Las exploraciones bolivianas, de reconocimiento y asentamiento, fueron a través del río Beni y el río Mamoré. Los exploradores dieron con la Cachuela Esperanza, un rápido de seis metros de caída por trescientos de extensión, donde se instaló la Casa Suárez y Hnos., y se creó la ciudad Cachuela Esperanza, la cual se convirtió en un punto estratégico desde donde se controlaba el flujo mercantil y de pasajeros. sólo después de 1880 "surgieron afirmadas empresas de mayor magnitud, asentadas en una o más barracas y con su producto puesto en el mercado internacional" (López Beltrán, 2001, p. 583).

A partir de la década de los noventa, los mismos empresarios de la goma comenzaron a desplazarse hacia el norte hasta el río Acre o Aquiry y el río Purus. Además, el Gobierno boliviano envió en 1892, 1895 y 1897 expediciones de reconocimiento, dirigidas por José Manuel Pando (López Beltrán, 2001, pp. 583-584).

Las poblaciones que comenzaron a surgir en estas zonas estaban motivadas por la explotación de la goma y por los mismos empresarios, que en muchos casos traían pobladores de otras regiones para trabajar en sus industrias. En el caso de Bolivia, los trabajadores venían con contratos por "enganche", es decir, por endeudamiento. En cambio, desde el Brasil, el territorio del Acre fue poblado "a goteo", más específicamente, por personas que fueron desplazadas desde las regiones del Bajo Amazonas, debido a las sequías y a la falta de alimentos (López Beltrán, 2001, pp. 584-585).

Para 1900, la industria de la goma era una amplia red que involucraba a múltiples grupos sociales y a varios países desarrollados. El éxito de esta industria puso en evidencia los intereses contrapuestos de los grupos económicos regionales llegados desde diferentes lugares (López Beltrán, 2001, p. 587).

Los problemas entre estos países surgieron en dos momentos distintos. El primer conflicto tuvo lugar en la década de los sesenta, y se terminó momentáneamente el problema con la firma del Tratado de Ayacucho, en 1867. El mismo fijaba la frontera entre estos países a través de una línea recta entre los núcleos de Esperanza y Río Branco (García Pérez, 2005, p. 226, ver el mapa 3).

El segundo período de enfrentamientos se dio cuando Bolivia decidió fundar Puerto Alonso (Zambrana Lara, 2011, p. 8). Sus intenciones eran imponer su soberanía sobre su territorio, además de crear una aduana e imponer impuestos a la goma (López Beltrán, 2001, pp. 587589). El gobernador del estado del Amazonas no vio con buenos ojos el establecimiento de la aduana boliviana y, aprovechando la situación, acusó ante su Gobierno la ilegalidad de la ocupación, culpando a los ocupantes bolivianos de robos, atropellos y actos de violencia cometidos contra los residentes brasileños (López Beltrán, 2001, pp. 587-589).

Los enfrentamientos armados movilizaron a siringueros (los trabajadores de los árboles de caucho o siringa) de toda la región, con victorias y derrotas de ambos lados; a estas primeras revueltas se llamaron, desde el lado boliviano, la Primera Campaña, y desde el lado brasilero, la Revolución del Acre (López Beltrán, 2001, pp. 587-589).

8 La Casa Suárez Suárez y Hnos. fue la mayor empresa exportadora de goma en Bolivia.

tiempo\&economía

$\mathrm{N}^{\circ} 2$ - I semestre de 2015

p. 81

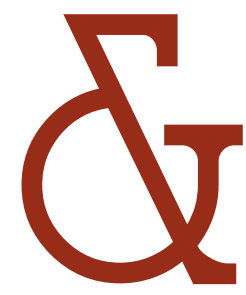


Mapa 3. Mapa que delimita cómo se dividió la región del Acre, y la zona que corresponde a cada país.

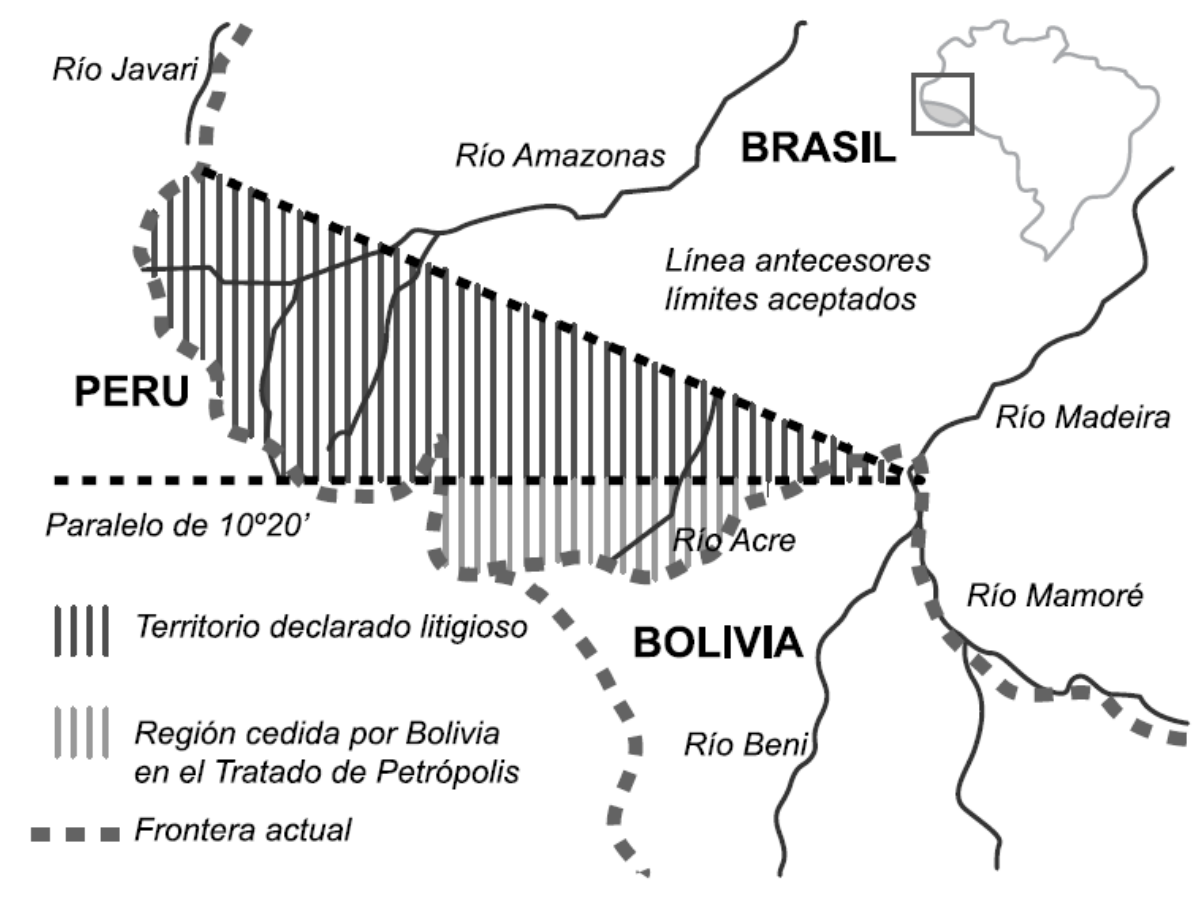

Fuente: elaboración propia con base al mapa: http://turma.spaceblog.com.br/147484/ACRE--Tratado--de-- Petropolis--antes--e--depois/

Zona demarcada por encima del paralelo de $10^{\circ} 20^{\prime}$ : Territorio declarado litigioso, zona cedida a Brasil en el Tratado de Ayacucho.

\section{Motivaciones económicas sobre la región del Acre y la explotación del caucho}

En esta sección se muestran los volúmenes de exportaciones de caucho para Brasil, así como también sus índices de precios en el mercado internacional. No se han incluido las exportaciones de Bolivia, por falta de datos. La idea de esta sección es poder cuantificar el crecimiento de la demanda internacional del caucho, así como el impacto que tuvo la variación de los precios sobre la explotación del mismo.

Como podemos ver en el gráfico 1, a partir de 1850 las exportaciones de caucho comenzaron a crecer de forma constante, aunque no fue sino hasta finales de la década de los ochenta que las exportaciones dieron una salto importante, debido a la invención de la rueda neumática (que, como ya se ha resaltado, se dio en 1888). A partir de allí, el crecimiento de las exportaciones fue aún más importante, llegando a su clímax en 1910. 
Gráfico 1. Exportaciones de caucho, en miles de toneladas métricas, para el período que va desde 1850 hasta 1910.

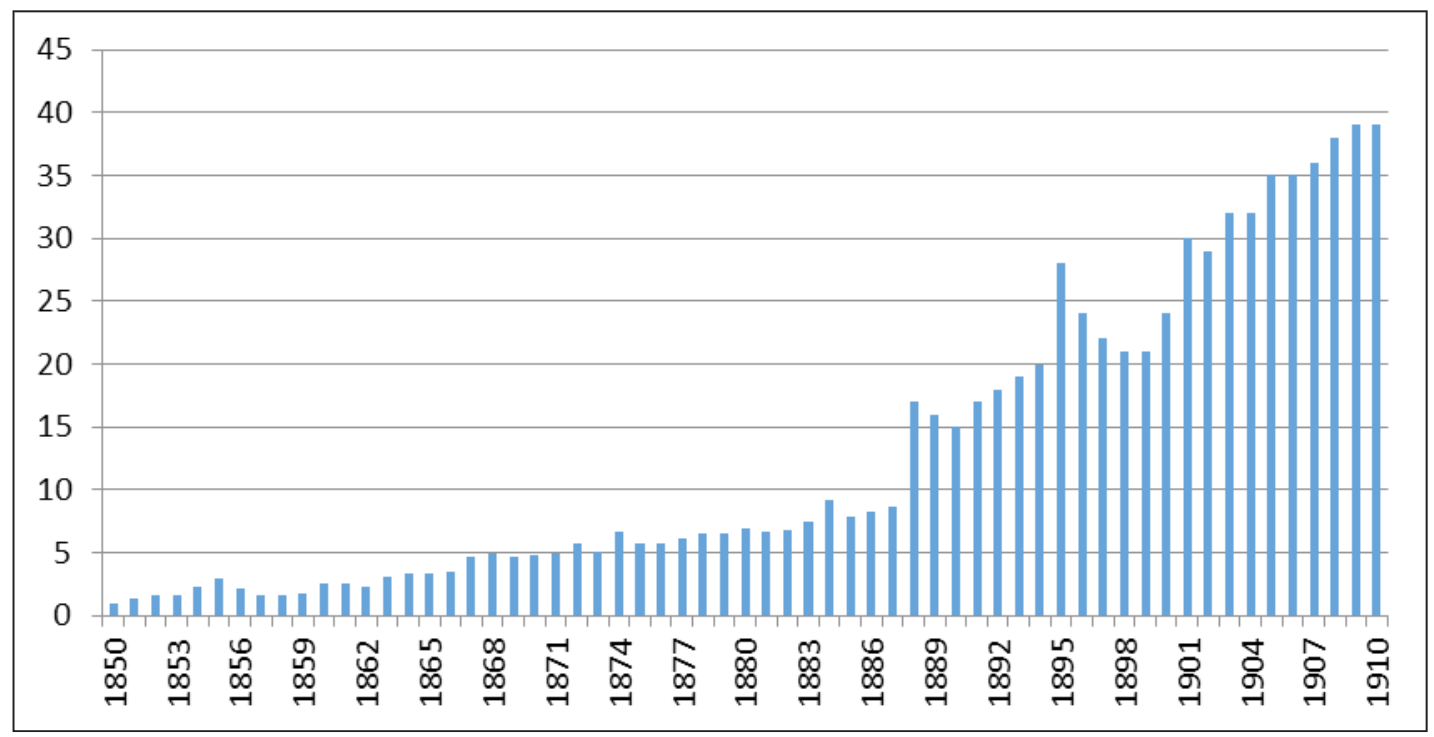

Fuente: elaboración con base en Mitchell, B. R. (2003), International Historical Statistics. The Americas 1750-2000, Fifth Edition. Palgrave Macmillan.

Exportación de caucho de Brasil para el período que va desde 1825 a hasta 1981.

Como se puede observar en el gráfico, en el período en que se disputó la región del Acre, las exportaciones de caucho eran elevadas y seguían presentando aumentos considerables. Si observamos el gráfico 2, podemos ver que los índices de precios internacionales presentaron una tendencia creciente entre 1870 y 1910.

Si se tiene en cuenta que la variabilidad de los índices de precios se puede haber correspondido con los cambios en la demanda del caucho, sería interesante ver el valor de las exportaciones de caucho. Lamentablemente, no se ha conseguido el valor de las exportaciones brasileras de caucho, por lo que se ha elaborado un índice de valores multiplicando las exportaciones (en miles de toneladas métricas) por el índice del precio del caucho en los mercados internacionales (ver el gráfico 3). Este índice permite analizar la evolución de las exportaciones en volúmenes integrando las variaciones de los precios. 
Gráfico 2. Índice de precios internacionales del caucho para el período que va desde 1870 hasta 1910.

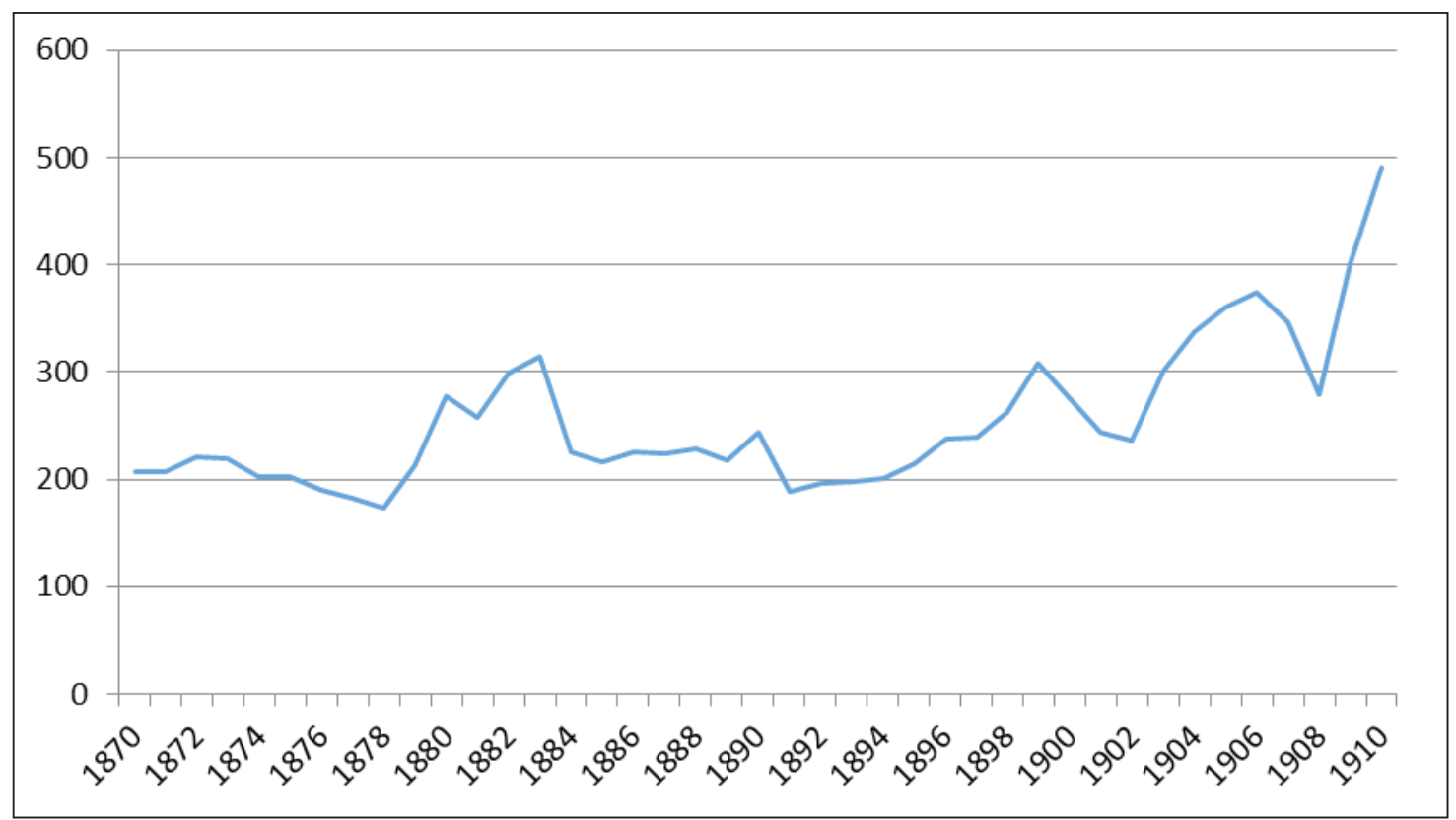

Fuente: elaboración propia con datos extraídos de la siguiente base de datos: MOxLAD. Index of Rubber Market Prices $(1970=100)$.

Gráfico 3. Índice de valores para el caucho en el período que va desde 1870 hasta 1910.

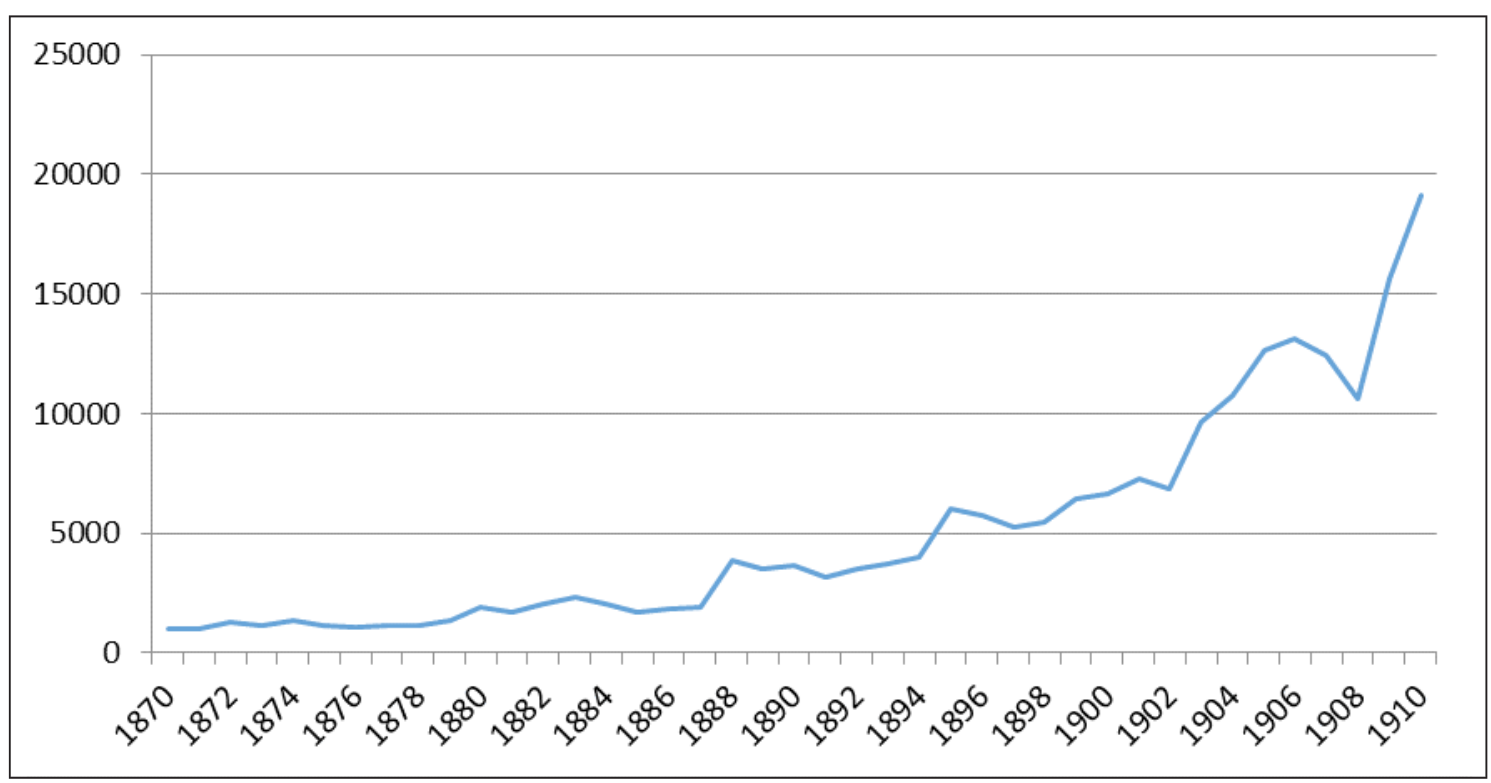

Fuente: elaboración propia con datos extraídos de la siguiente base de datos: MOxLAD. Index of Rubber Market Prices (1970). datos de volúmenes de Mitchell, B. R. (2003) International Historical Statistics. The Americas 1750-2000, Fifth Edition. Palgrave Macmillan. Este gráfico se calculó multiplicando el índice de precios del caucho por el volumen de las exportaciones, para poder ver si las caídas de precios se correspondían con aumentos en los niveles de exportaciones. 
En este gráfico se observa claramente cómo crece el valor de las exportaciones a lo largo de las décadas de finales del siglo XIX. Un resultado muy similar al que se obtenía con el gráfico de volúmenes exportados (véase el gráfico 1).

Si bien, el volumen de exportaciones de caucho es significativo, al nivel nacional es difícil ponerlo en contraste. Brasil es un país muy grande, con muchas regiones y una población muy numerosa. Aun así, son los mensajes que el mercado enviaba a aquellos interesados en instalar industrias de goma en la región del Acre lo que se destaca aquí. Claramente, las posibilidades de expansión de la industria y las percepciones de los inversores a la hora de elegir un rubro donde invertir son muy importantes, y las señales que el mercado enviaba a fines del siglo XIX eran muy favorables para la instalación de estas industrias. Como bien destacan Bevilaqua y Paiva Abreu (2003):

Las exportaciones de caucho provenientes de la región Amazónica se tornaron importantes en los años 1890, que alcanzaron en 1910 casi $40 \%$ del total de exportaciones brasileñas [...]. Las exportaciones de caucho fueron una fuente importante de generación de divisas, particularmente en el decenio de oro antes de la Primera Guerra Mundial. (Bevilaqua y Paiva Abreu, 2003, p. 61).

\section{Algunas conclusiones}

La falta de evidencia empírica del período de las post-independencias ha llevado a la sobrestimación de la herencia colonial como factor determinante del desarrollo económico y también ha llevado a sobrestimar la importancia de la demanda internacional de bienes. Las decisiones de política interna claramente estarán afectadas por estas dos variables, pero no son por sí solas las únicas causas por tener en cuenta. La situación interna de cada país, los conflictos políticos, sociales, militares y económicos, son variables relevantes por incorporar en el análisis.

En este trabajo se busca integrar más variables al análisis histórico-económico de América Latina, vinculando los procesos de independencia, la formación de los Estados y la determinación de sus fronteras con las posibilidades de desarrollo para fines de la primera globalización. Como se puede observar en el trabajo, ya desde la época colonial, los territorios brasileros y bolivianos presentaban escenarios políticos y económicos muy disímiles. La transición de colonias a países independientes fue muy diferente en cada uno de los casos analizados en este trabajo.

Bolivia sufrió por su inestabilidad política en el período de formación de su Estado, no sólo porque hubo enfrentamientos dentro de la clase dirigente boliviana, sino que además porque se hizo un uso indebido de los recursos del Estado. Brasil, en cambio, vivió un proceso totalmente distinto al de Bolivia. El paso de colonia a imperio y luego a país independiente terminó beneficiando a este país, ya que hubo una aparente estabilidad política que generó instituciones que protegieron a los grupos económicos de la expropiación de los recursos naturales. 
En cuanto a los aspectos económicos, Brasil fue desde la Colonia una economía muy diversificada, y el paso de colonia a imperio, y luego a país independiente, no modificó su estructura de exportación. Principalmente, la ventaja más importante de la economía brasilera es que el paso de Colonia a Imperio no obligó al país a buscar nuevos mercados, no se dedicaron recursos a la búsqueda de nuevos bienes ni se redujeron sus exportaciones en el corto plazo. En cambio, Bolivia vivió un período de estancamiento de sus exportaciones en el período de la post-independencia, debido, principalmente, al fin del monopolio con España. El Estado destinó recursos y tiempo a buscar nuevos mercados, así como nuevos bienes para exportar (el caucho fue uno de ellos). Para 1850 se reactivó la explotación de la plata, pero esta tuvo límites para afectar al resto de la economía. Además, las exportaciones que se llevaban a cabo desde el litoral boliviano - guano, cobre, y luego salitre - estaban libres de impuestos y eran explotadas por empresas extranjeras.

La región del Acre fue disputada, como ya quedó establecido en el trabajo, por la existencia del árbol del caucho y la creciente demanda internacional de la goma, debido, sobre todo, a la invención de la rueda neumática. Brasil terminó por hacerse del territorio que desde la Colonia correspondía a territorio español. Aquí se ha intentado demostrar que esta expropiación no es ajena al poder de los Estados durante este período. Brasil tenía una estructura económica y política que le permitía hacer frente a una disputa territorial; en cambio, Bolivia no tenía ni recursos ni estabilidad política para hacer frente a semejante travesía. Además, el Estado boliviano estaba en búsqueda de un nuevo bien que le permitiera desarrollarse económicamente; en cambio, Brasil ya tenía una estructura de exportación sólida.

La metodología seguida en el estudio ha consistido en el análisis bibliográfico acerca de los orígenes y desarrollos de las teorías que explican las diferencias regionales de desarrollo para el siglo XIX, la descripción a partir de fuentes secundarias del conflicto objeto de estudio y el desarrollo de una primera aproximación cuantitativa a fuentes primarias, además de la elaboración propia de evidencia empírica para el caso del caucho. En futuros desarrollos de esta investigación se prevé incorporar al análisis la fiscalidad de los Estados brasileros y bolivianos así como también la fuerza de las inversiones inglesas en estos países para el siglo XIX, ya que ambas variables son claves para entender la fuerza de estos Estados en el período analizado.

\section{Referencias}

Acemoglu, D., Johnson, S., Robinson, J. A. (2002). Reversal of Fortune: Geography and Institutions in the Making of the World Income Distribution. The Quarterly Journal of Economics, 117, pp. 1231-1294.

Arroyo Abad, L. (2013). Persistent Inequality? Trade, Factor Endowments, and Inequality in Republican Latin America. The Journal of Economic History, 73, pp. 38-78.

Bethel, L. y Carvalho, J. M. (1991). Brasil (1822-1850). En L. Bethel, (Ed.), Historia de América Latina: América Latina independiente 1820 -1870, pp. 319-377. Bethel, L. (Ed.). Barcelona: Editorial Crítica. 
Bevilaqua, A. y Paiva Abreu, M. (2003). Brasil como una economía exportadora, 1880-1930. En E. Cárdenas, J. A. Ocampo, y Thorp, R. (coords.), La era de las exportaciones latinoamericanas: desde fines del siglo XIX a principios del XX, pp. 54-84. E. Cárdenas, J. A. Ocampo, y Thorp, R. (coords.). México: Fondo de Cultura Económica.

Bonilla, H. (1991). Perú y Bolivia. En L. Bethel, (Ed.), Historia de América Latina: América Latina independiente 1820-1870, pp. 202-237. Bethel, L. (Ed.). Barcelona: Editorial Crítica.

Bulmer-Thomas, V. (2000) La historia económica de América Latina desde la Independencia. México: Fondo de Cultura Económica.

Carmagnani, M. (1984). Estado y sociedad en América Latina 1850-1930. Barcelona: Editorial Crítica.

Caselli, F., Morelli, M. y Rohner, D. (2013) The Geography of Inter-State Resource Wars. National Bureau of Economic Research (NBER) Working Paper No. 18978. http://www.nber.org/papers/ w18978.

Dean, W. (1987). Brazil and the Struggle for Rubber. Cambridge: Cambridge University Press.

Dean, W. (1992). La economía brasileña, 1870-1930. En L. Bethel (Ed.), Historia de América Latina: América del Sur, c. 1870-1930, pp. 333-369. Bethel, L. (Ed.). Barcelona: Editorial Crítica.

Deler, J-P. (2008). Transformación del espacio en América Latina. En E. Ayala Mora, (dir.), Historia general de América Latina. (Vol. VII): Los proyectos nacionales latinoamericanos: sus instrumentos y articulación, 1870-1930, pp. 33- 58. Ayala Mora, E. (dir.). París: Unesco.

García Pérez, J. (2005). Conflictos territoriales y luchas fronterizas en América Latina durante los siglos XIX y XX. Norba Revista de Historia, 18, pp. 215-241.

Haber, S. H. y Klein, H. S. (1993). Consecuencias económicas de la independencia brasileña. En L. Prados de la Escosura y S. Amaral (eds.), La independencia americana: consecuencias económicas, pp. 147-163. Madrid: Alianza Editorial.

López Beltrán, C. (2001). La exploración y la ocupación del Acre. Revista de Indias, LXI, 223, pp. 573-590

Mitchell, B. R. (2003). International Historical Statistics. The Americas 1750-2000. New York: Palgrave Macmillan.

Palma, G. (2003). La economía chilena desde la Guerra del Pacíico a la Gran Depresión: cómo evitar el síndrome holandés por medio de "gravar, transferir y gastar". En E. Cárdenas, J. A., Ocampo, R. Thorp, (coords.), La era de las exportaciones latinoamericanas: desde fines del siglo XIX a principios del XX, pp. 297-359. México: Fondo de Cultura Económica.

Peres Cajías, J. A. (2011). Potosí ya no valía un Potosí. El impacto económico de la Independencia en Bolivia". X Congreso Internacional de la AEHE.

Prados de la Escosura, L. (2006). The Economic Consequences of Independence in Latin America. En V. BulmerThomas, J. Coatsworth y R. Cortes Conde (coords.), The Cambridge Economic History of Latin America, pp. 463-504. Cambridge: Cambridge Histories Online ( Cambridge University Press, http://dx.doi.org/10.1017/CHOL9780521812894.015. 
Prados de la Escosura, L. (2009). Lost Decades? Economic Performance in Post-Independence Latin America. Journal of Latin America Study, 41, pp. 279-307. DOI: 10.1017/ S0022216X09005574

Sicotte, R., Vizcarra, C. y Wandschneider, K. (2008). The Fiscal Impact of the War of the Pacific. Cliometrica, 3, pp. 97-121. DOI: 10.1007/s11698-008-0028-6

Ullán de la Rosa, F. J. (2004). La era del caucho en el Amazonas (1870-1920): modelos de explotación y relaciones sociales de producción. Anales del Museo de América, 12, pp. 183-204.

Zambrana Lara, C. G. (2011). Historia fotográfica del puerto de Cobija (1908). Revista de la Biblioteca y Archivo Histórico de la Asamblea Legislativa Plurinacional, 5, pp. 5-13.

\section{Fuentes de mapas:}

Mapa 1: http://commons.wikimedia.org/wiki/File:Amazonriverbasin_basemap.png.

Mapa 2: http://noss2geografia.blogspot.com.es/2012/02/o-territorio-legalizado-os-tratados. html.

Mapa 3: http://turma.spaceblog.com.br/147484/ACRE-Tratado-de-Petropolis-antes-e-depois/

Fuentes de datos:

MOxLAD: Index of Rubber Market Prices (1970=100). http://moxlad.fcs.edu.uy/

Tratado de Petrópolis: http://www.rree.gob.bo/webmre/dglfai/Tratados\%20HTML/brasil/Tratado\%20de\%20Petropolis.html 